\title{
An Innovative Study for non-Newtonian Behaviour of Blood Flow in Stenosed Artery using Herschel-Bulkley Fluid Model
}

\author{
Sapna Ratan Shah \\ Department of Mathematics \\ Harcourt Butler Technological Institute, Kanpur - 208002, (India) \\ Fax No.0512-2533812, E-mail:sapna1980jan@rediffmail.com
}

\begin{abstract}
This innovative model is presented to study the effect of non-Newtonian behavior of blood flow through a radially non-symmetric multiple stenosis artery using Herschel-Bulkely fluid model. The numerical illustration presented at the end of the paper provides the results for the resistance to flow, apparent viscosity and the wall shear stress through their graphical representations. It has been shown that the resistance to flow, apparent viscosity and wall shear stress increases with the size of the stenosis but these increases is comparatively small due to non-Newtonian behavior of the blood indicating the usefulness of its rheological character in the functioning of the diseased arterial circulation. Few comparisons with the existing results have been made in order to validate the applicability of the present model.
\end{abstract}

Keywords: Non-Newtonian fluid, Herschel-Bulkley fluid, Resistance to flow, Wall shear stress, Apparent viscosity, Radially non-symmetric multiple stenosis

\section{Introduction}

It is well known that whole blood, even during steady flow through rigid cylindrical tubes, does not behave as a Newtonian fluid. Instead, the velocity profile for blood changes from the parabolic shape of an ideal liquid to a blunter one, and along with this, there is a migration of erythrocytes away from the vessel wall. This change increases progressively as the vessel diameter decreases. Homogeneous liquids may behave closely like Newtonian fluids. However, there are fluids that do not obey the linear relationship between shear stress and shear strain rate. Fluids that exhibit a non-linear relationship between the shear stress and the rate of shear strain are called non-Newtonian fluids. Blood behaviour is referred to as nonNewtonian properties. These properties are of two types as follows: (a) at low shear rates the apparent viscosity increases markedly. Sometimes even a certain yield stress is required for flow. (b) In small tubes, the apparent viscosity at higher rates of shear is smaller than it is in larger tubes. These two types of anomalies are often referred to as low shear and high shear effects respectively. It is thus concluded that the behaviour of blood is almost Newtonian at high shear rate, while at low shear rate the blood exhibits yield stress and non-Newtonian behaviour. In the series of the papers, [Texon, (1) May et al., (2) Hershey and Cho, (3) Young, (4) Forrester and Young, (5) Caro et al., (6) Fry (7) Young and Tsai, (8) Lee, (9); Richard et al., (10)] effects on the cardiovascular system can be understood by studying the blood flow in its vicinity. In these studies the behavior of the blood has been considered as a Newtonian fluid. However, it may be noted that the blood does not behave as a Newtonian fluid under certain conditions. It is generally accepted that the blood, being a suspension of cells, behaves as a non-Newtonian fluid at low shear rate [Charm and Kurland, (11); Hershey et al., (12) Whitemore, (13); Cokelet, (14); Lih, (15); Shukla et al., (16)]. It has been pointed 
out that the flow behaviour of blood in a tube of small diameter (less than $0.2 \mathrm{~mm}$ ) and at less than $20 \mathrm{sec}^{-1}$ shear rate, can be represented by a power-low fluid [Hershey et al., (12); Charm et al., (11)]. It has also been suggested that at low shear rate $\left(0.1 \mathrm{sec}^{-1}\right)$ the blood exhibits yield stress and behaves like a Casson-model fluid [Casson, (17); Reiner and Scott-Blair, (18); Charm et al., (11)]. For blood flows in large arterial vessels (i.e., vessel diameter $\geq 1 \mathrm{~mm}$ ) [Labarbera, (19), Jung (23), Pralhad (24), Venkateshwarlu (25) Sanyal (26), Rathod (27) Singh (28), Mishra (29), Singh (30)], which can be considered as a large deformation flow, the predominant feature of the rheological behavior of blood is its shear rate dependent viscosity, and its fact on the hemodynamics of large arterial vessel flows has not been understood well. In this paper we investigated the effect of non-Newtonian behaviour of blood flow on the resistance to flow, apparent viscosity and wall shear stress in an stenosed artery by considering blood as a Herschel-Bulkely fluid model. Blood flow is considered through an axially non-symmetrical but radially symmetric stenosis (shown in Figure 1.(a)).

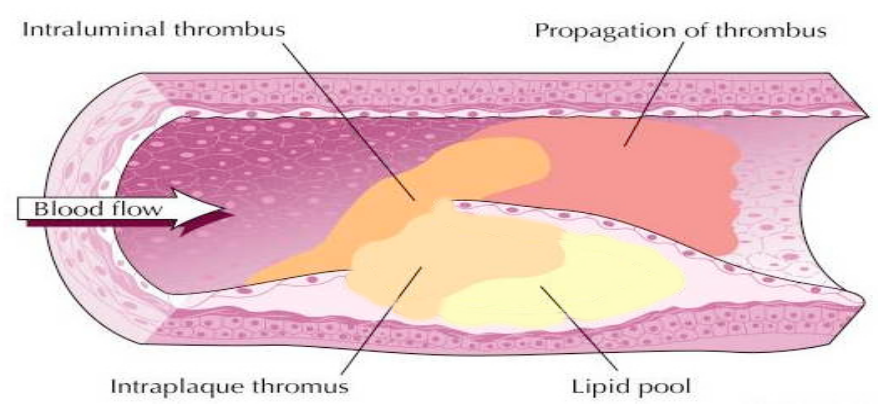

Figure 1.(a). Stenosis

\section{Formulation of the Problem:}

In the present analysis, it is assumed that the stenosis develops in the arterial wall and symmetrical about the axis but non-symmetrical with respect to radial co-ordinates. In such a case the radius of artery, R(z) can be written as: Figure 1.(b)

$$
\begin{aligned}
\frac{\mathrm{R}(\mathrm{z})}{\mathrm{R}_{0}} & =\left(\begin{array}{cc}
1-\mathrm{A}\left[\mathrm{L}_{0}^{(\mathrm{m}-1)}\left(\alpha \mathrm{z}-\mathrm{kd}-(\mathrm{k}-1) \mathrm{L}_{0}\right)\right. \\
& \left.-\left(\alpha z-\mathrm{kd}-(\mathrm{k}-1) \mathrm{L}_{0}\right)^{\mathrm{m}}\right]
\end{array}\right) ; & & \mathrm{k}\left(\mathrm{d}+\mathrm{L}_{0}\right)-\mathrm{L}_{0} \leq \alpha \mathrm{z} \leq \mathrm{k}\left(\mathrm{d}+\mathrm{L}_{0}\right) \\
& =1 ; & & \text { otherwise }
\end{aligned}
$$

where $\mathrm{A}=\frac{\delta}{\mathrm{R}_{0} \mathrm{~L}_{0}^{\mathrm{m}}} \frac{\mathrm{m}^{\mathrm{m} /(\mathrm{m}-1)}}{(\mathrm{m}-1)}$

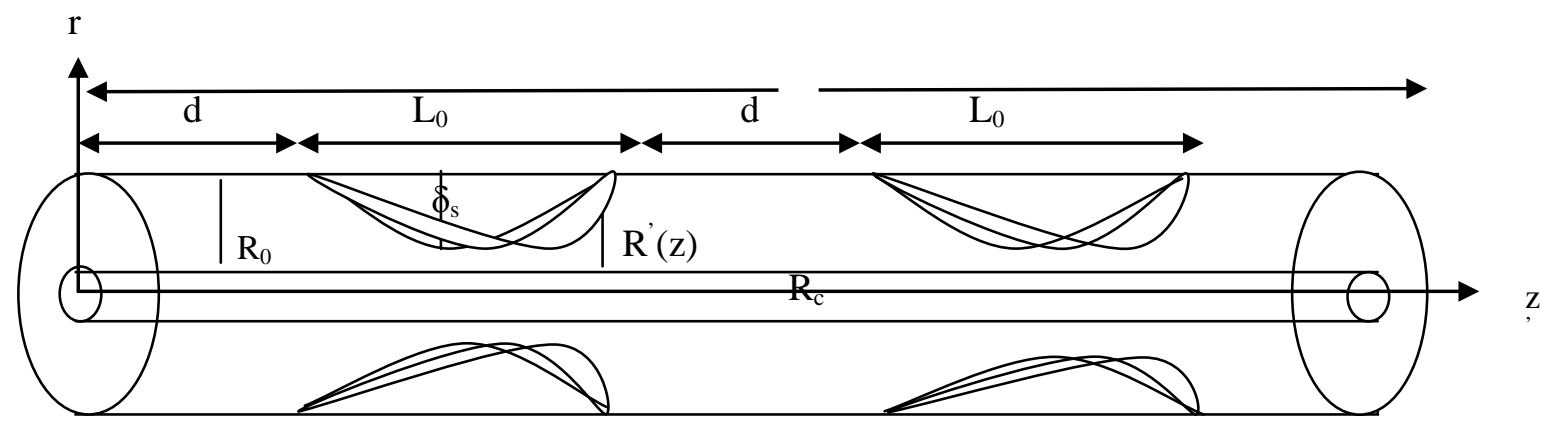

Figure 1.(b). Geometry of Stenosed Artery 
$\mathrm{R}(\mathrm{z})$ and $\mathrm{R}_{0}$ is the radius of the artery with and without stenosis, respectively. $\mathrm{L}$ is the length of artery and $L_{0}$ is the stenosis length, $d$ indicates the distance between equispaced points, $k$ is number of stenosis that appears in arterial lumen, $\alpha$.is a positive integer $\geq \mathbf{1}, \mathrm{m}$ is parameter determining the shape of stenosis in artery and $\delta$ denotes the maximum height of stenosis at

$\mathrm{z}=\left[\frac{\mathrm{kd}+(\mathrm{k}-1) \mathrm{L}_{0}+\mathrm{L}_{0} / \mathrm{m}^{1 /(\mathrm{m}-1)}}{\alpha}\right]$.

2.1. Herschel-Bulkley Fluid Model: The stress-strain relation of Herschel-Bulkley fluid is given as:

$$
\begin{array}{ll}
\mathrm{f}(\tau)=\left(-\frac{\mathrm{du}}{\mathrm{dr}}\right)=\frac{1}{\mu}\left(\tau-\tau_{\mathrm{o}}\right)^{\mathrm{n}}, & \tau \geq \tau_{0} \\
\mathrm{f}(\tau)=\left(-\frac{\mathrm{du}}{\mathrm{dr}}\right)=0, & \tau \leq \tau_{0} \\
\text { where } \tau=\left(-\frac{\mathrm{dp}}{\mathrm{dz}} \frac{\mathrm{r}}{2}\right), & \tau_{\mathrm{o}}=\left(-\frac{\mathrm{dp}}{\mathrm{dz}} \frac{\mathrm{R}_{\mathrm{c}}}{2}\right),
\end{array}
$$

and $\mu$ denotes Herschel-Bulkley viscosity coefficient, $\tau_{o}$ is yield stress, $\tau$ is shear stress, $R_{c}$ is the radius of the plug-flow region, $\mathrm{u}$ is the axial velocity along the $\mathrm{z}$ direction and $\mathrm{n}$ is the flow behavior index. The relation correspond to the vanishing of the velocity gradients in regions, in which the shear stress $\tau$ is less than the yield stress $\tau_{0}$ this implies a plug flow wherever $\tau \leq \tau_{0}$ when the shear rates in the fluid are very high, $\tau \geq \tau_{0}$, the power-law fluid behavior is indicated.

\subsection{Conservation Equation and Boundary Condition:}

The equation of motion for laminar and incompressible, steady, fully-developed, onedimensional flow of blood whose viscosity varies along the radial direction in an artery reduces to:

$$
\left.\begin{array}{l}
\mathbf{O}=-\frac{\partial \mathbf{P}}{\partial \mathbf{r}}+\frac{\mathbf{1}}{\mathbf{r}} \frac{\partial(\mathbf{r} \tau)}{\partial \mathbf{z}}, \\
\mathbf{O}=-\frac{\partial \mathbf{P}}{\partial \mathbf{r}},
\end{array}\right\}
$$

where $(\mathrm{z}, \mathrm{r})$ are co-ordinates with $\mathrm{z}$ measured along the axis and $\mathrm{r}$ measured normal to the axis.

Following boundary conditions are introduced to solve the above equations,

$$
\begin{array}{lll}
\partial \mathrm{u} / \partial \mathrm{r}=\mathrm{O} & \text { at } \mathrm{r}=\mathrm{O} & \\
\mathrm{u}=\mathrm{O} & \text { at } \mathrm{r}=\mathrm{R}(\mathrm{z}), \tau \text { is finite } & \text { at } \mathrm{r}=\mathrm{O} \\
\mathbf{P}=\mathbf{P}_{\mathrm{O}} & \text { at } \mathrm{z}=\mathrm{O}, \quad \mathrm{P}=\mathrm{P}_{\mathrm{L}} & \text { at } \mathrm{z}=\mathrm{L}
\end{array}
$$

\section{Analysis of the Problem:}

By equation (2) and (3) we get,

$$
\left(\frac{\mathrm{du}}{\mathrm{dr}}\right)=-\left(\frac{\mathrm{p}}{2 \mu}\right)^{1 / \mathrm{n}}\left[\left(\mathrm{r}-\mathrm{R}_{\mathrm{c}}\right)^{1 / \mathrm{n}}\right] \text {, }
$$


the flow of flux, $\mathrm{Q}$, is defined as,

$$
\mathrm{Q}=\int_{0}^{\mathrm{R}} 2 \mathrm{p} \mathrm{u} \mathrm{r} \mathrm{dr}=\mathrm{p} \int_{0}^{\mathrm{R}} \mathrm{r}^{2}\left(-\frac{\mathrm{du}}{\mathrm{dr}}\right) \mathrm{dr}
$$

substituting the value of $f(\tau)$ from equation (4) in equation (6),

$$
\mathrm{Q}=\frac{\pi}{2}\left(\frac{\mathrm{P}}{2 \mu}\right)^{1 / \mathrm{n}} \frac{\mathrm{R}^{\left(3+\frac{1}{n}\right)}}{\left(1+\frac{1}{n}\right)} \mathrm{f}(\mathrm{y})
$$

where $f(y)=\left[2\left(1-\frac{R_{c}}{R}\right)^{((1 / n)+1)}-\frac{4}{((1 / n)+2)}\left(1-\frac{R_{c}}{R}\right)^{((1 / n)+2)}+\frac{4}{((1 / n)+2)((1 / n)+3)}\right.$

$\left.\left(\left(1-\frac{\mathrm{R}_{\mathrm{C}}}{\mathrm{R}}\right)^{((1 / \mathrm{n})+3)}-\left((-1)^{((1 / \mathrm{n})+3)}\left(\frac{\mathrm{R}_{\mathrm{C}}}{\mathrm{R}}\right)\right)\right)\right]$,

$\overline{\mathrm{y}}=\frac{\mathrm{R}_{\mathrm{C}}}{\mathrm{R}}<<1$.

Using equation (7) we have,

$$
P=\left(-\frac{d p}{d z}\right)=\frac{2 \mu}{R^{(1+3 n)}}\left(\frac{2 Q}{\pi f(\bar{y})}\left(1+\frac{1}{n}\right)\right)^{n}
$$

to determine $\lambda$, we integrate equation (8) for the pressure $P_{L}$ and $P_{0}$ re the ressure at $z=0$ and $\mathrm{z}=\mathrm{L}$, respectively, where $\mathrm{L}$ is the length of the tube.

$$
\Delta \mathrm{P}=\mathrm{P}_{\mathrm{L}}-\mathrm{P}_{0}=\frac{2 \mu}{\pi \mathrm{R}_{0}^{1+3 \mathrm{n}}}\left(2 \mathrm{Q}\left(\frac{1}{\mathrm{n}}+1\right)\right)^{\mathrm{n}} \int_{0}^{L} \frac{\mathrm{dz}}{\left(\mathrm{R}(\mathrm{z}) / \mathrm{R}_{0}\right)^{(1+3 \mathrm{n})}(\mathrm{f}(\overline{\mathrm{y}}))^{\mathrm{n}}}
$$

The resistance to flow is given by the coefficient $\lambda$ is define as follows:

$\lambda=\mathrm{P}_{\mathrm{L}}-\mathrm{P}_{0} / \mathrm{Q}$

on using equation (9) and (10) gives,

$$
\begin{aligned}
\lambda_{0} & =\frac{2 \mu}{R_{0}^{1+3 n}}\left(\frac{2 \mathrm{Q}\left(1+\frac{1}{n}\right)}{\pi}\right)^{\mathrm{n}}(\mathrm{M}) \\
\mathrm{M} & =\left(\int_{0}^{\mathrm{d}} \frac{\mathrm{dz}}{\left(\mathrm{f}_{0}\right)^{\mathrm{n}}}+\int_{\mathrm{d}}^{\mathrm{d}+\mathrm{L}_{0}} \frac{\mathrm{dz}}{\left(\frac{\mathrm{R}(\mathrm{z})}{\mathrm{R}_{0}}\right)^{1+3 \mathrm{n}}(\mathrm{f}(\overline{\mathrm{y}}))^{\mathrm{n}}}+\int_{\mathrm{d}+\mathrm{L}_{0}}^{2 \mathrm{~d}+\mathrm{L}_{0}} \frac{\mathrm{dz}}{\left(\mathrm{f}_{0}\right)^{\mathrm{n}}}+\int_{2 \mathrm{~d}+\mathrm{L}_{0}}^{2 \mathrm{~d}+2 \mathrm{~L}_{0}} \frac{\mathrm{dz}}{\left(\frac{\mathrm{R}(\mathrm{z})}{\mathrm{R}_{0}}\right)^{1+3 \mathrm{n}}(\mathrm{f}(\overline{\mathrm{y}}))^{\mathrm{n}}}\right)
\end{aligned}
$$




$$
f_{0}=\left[2\left(1-\bar{y}_{1}\right)^{\left(1+\frac{1}{n}\right)}-\frac{4}{\left(\frac{1}{n}+2\right)}\left(1-\bar{y}_{1}\right)^{\left(2+\frac{1}{n}\right)}+\frac{4}{\left(2+\frac{1}{n}\right)\left(3+\frac{1}{n}\right)}\left(\left(1-\bar{y}_{1}\right)^{\left(3+\frac{1}{n}\right)}-\left((-1)^{\left(3+\frac{1}{n}\right)} \bar{y}_{1}\right)\right)\right] \text {, }
$$

where $\overline{\mathrm{y}}_{1}=\frac{\mathrm{R}_{\mathrm{c}}}{\mathrm{R}_{0}}$

When there is no stenosis in artery then $\mathrm{R}=\mathrm{R}_{0}$, the resistance to flow,

$$
\lambda_{N}=\frac{2 \mu}{R_{0}^{1+3 n}}\left(\frac{2 Q\left(1+\frac{1}{n}\right)}{\pi}\right)^{n} \frac{L}{\left(f_{0}\right)^{n}}
$$

from equation (10) and (11) the ratio of $(\lambda / \lambda N)$ is given as:

$$
\lambda=\frac{\lambda_{0}}{\lambda_{\mathrm{N}}}=1-\frac{\mathrm{L}_{0}}{\mathrm{~L}}+\frac{\left(\mathrm{f}_{0}\right)^{\mathrm{n}}}{\mathrm{L}} \int_{\mathrm{d}}^{\mathrm{d}+\mathrm{L}_{0}} \frac{\mathrm{dz}}{\left(\frac{\mathrm{R}(\mathrm{z})}{\mathrm{R}_{\mathrm{o}}}\right)^{1+3 \mathrm{n}} \mathrm{f}(\overline{\mathrm{y}})^{\mathrm{n}}}
$$

The apparent viscosity $\left(\mu_{0} / \mu\right)$ is defined as follow:

$$
\mu_{\mathrm{app}}=\frac{1}{\left(\frac{\mathrm{R}(\mathrm{z})}{\mathrm{R}_{0}}\right)^{1+3 \mathrm{n}} \mathrm{f}(\overline{\mathrm{y}})}
$$

\section{Results and Discussion}

Figure (2) consists the variation of resistance to flow $(\lambda)$ with stenosis size $\left(\delta / R_{0}\right)$ for different values of stenosis length. It is observed here that the resistance to flow increases as the stenosis size increases. It should be also noted here that the resistance to flow increases as stenosis length increases. Our results are therefore consistent with the observation of [9].

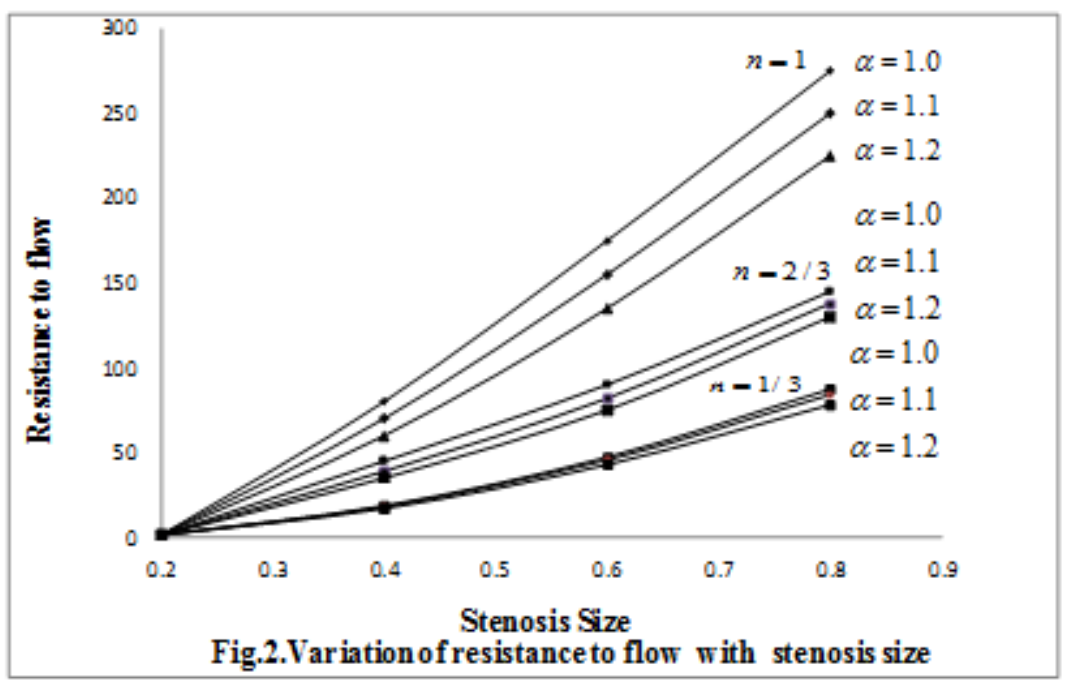

Figure 2. Variation of Resistance to Flow with Stenosis Size 


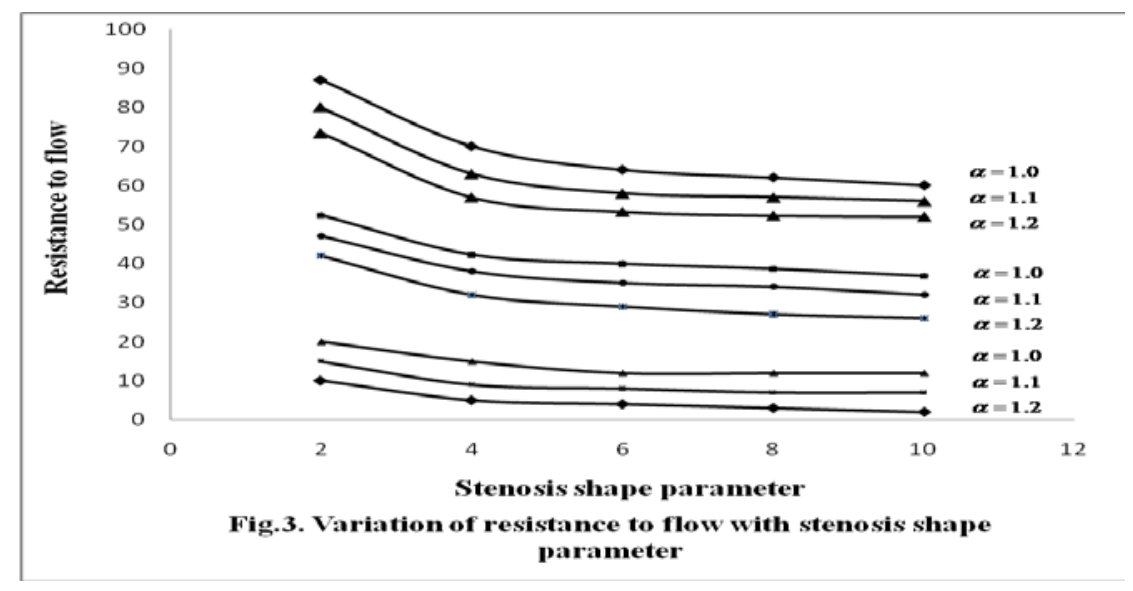

Figure 3. Variation of Resistance of Flow with Stenosis Shape Parameter

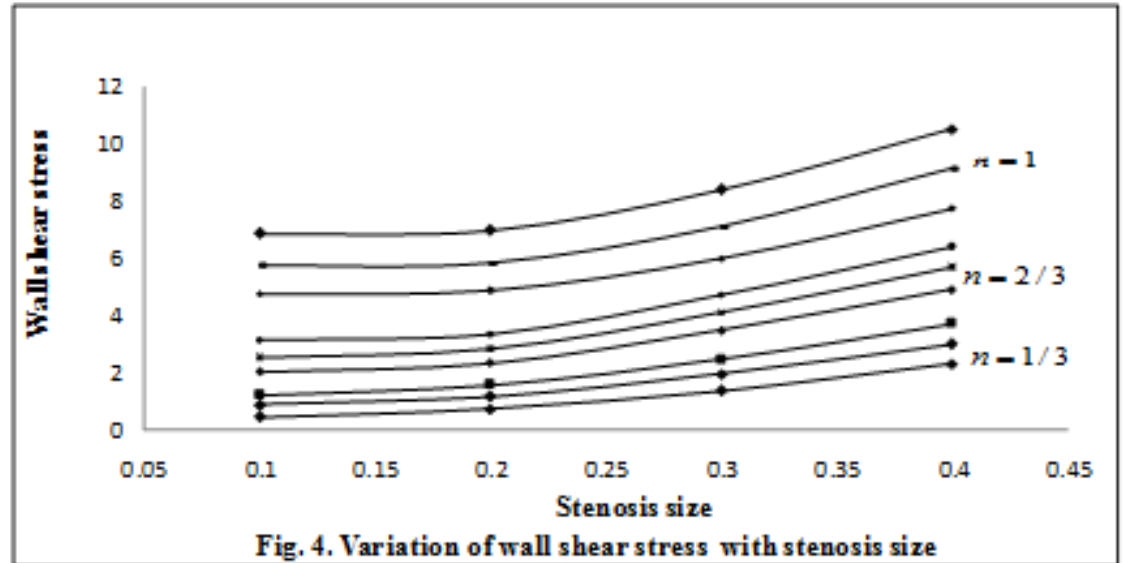

Figure 4. Variation of Wall Shear Stress with Stenosis Size

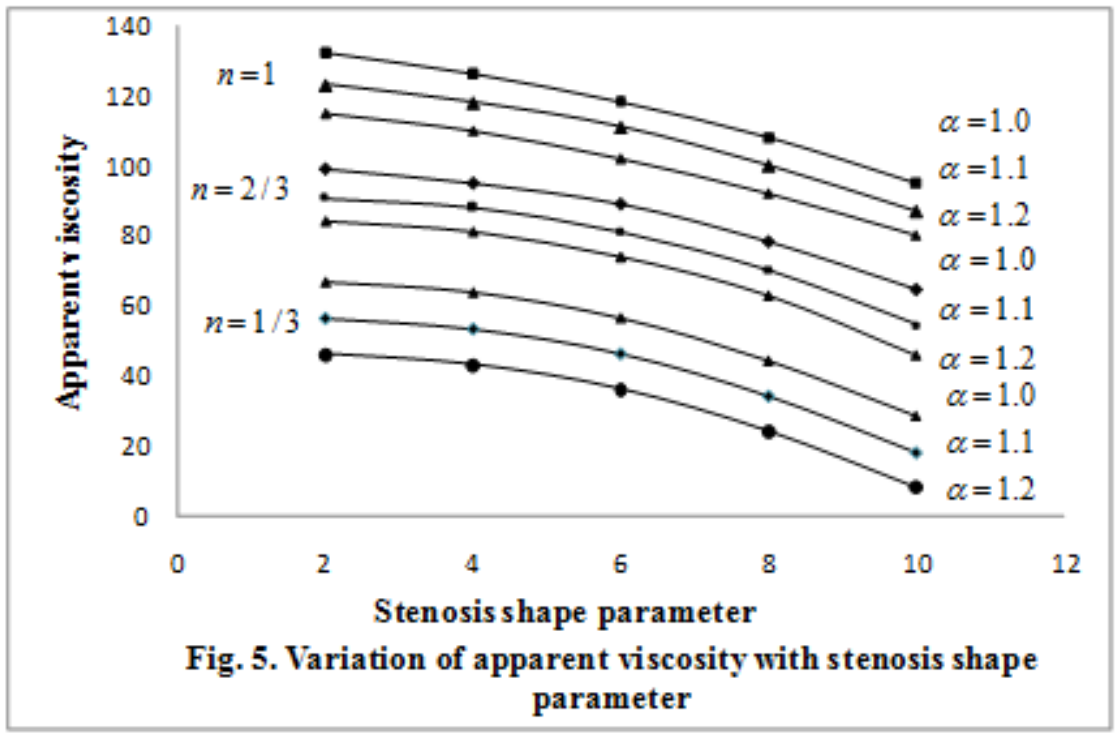

Figure 5. Variation of Apparent Viscosity with Stenosis Shape Parameter 
Figure (3) describes the variation of resistance to flow $(\lambda)$ with stenosis shape parameter (m). In this graph, resistance to flow increases as stenosis length increases. It is also noticed here that resistance to flow decreases as stenosis shape parameter increases. This result is obvious because the lumen radius decreases as stenosis size increases [14]. Figure (4) depicts the variation of wall shear stress for different values of stenosis size. It is evident from the graph that the wall shear stress increases as stenosis size increases. This graph is also highlighted that wall shear stress increases as non-Newtonian behavior (n) increases [20]. Figure (5) reveals the variation of apparent viscosity $\left(\mu_{0} / \mu\right)$ with stenosis shape parameter $(\mathrm{m})$ for different values of stenosis size $\left(\delta / R_{0}\right)$. It may be observed here that the apparent viscosity decreases as shape parameter of stenosis increases. This figure is also depicted that apparent viscosity increases as stenosis size increases. In an artery flow, the viscosity of blood found to vary with the arterial radius decreasing with it. The diabetic patients are more prone to the various cardiovascular diseases. The viscosity of the diabetic patients is higher than that of normal. Therefore the blood viscosity of diabetic patients is lowered by regular dose of aspirin or injecting saline water in order to dilute the blood [12]. This lowers the blood pressure.

\section{Conclusion}

Blood flow through an artery mainly depends on the pressure gradient and resistance to flow. Resistance to flow increases as the stenosis grows and remains constant outside the stenotic region. In this paper the behavior of non-Newtonian flows in an radially nonsymmetric multiple stenosed artery by considering the blood as Herschel-Bulkley fluids is studied. It has been concluded that the resistance to flow and wall shear stress increases as the size of stenosis increases for a given non-Newtonian model of the blood. These increases are however, small due to non-Newtonian behaviour of the blood. It has also been concluded that the apparent viscosity increases as yield stress increases and decreases as stenosis shape parameter increases. The results were greatly influenced by the change of stenosis shape parameter. In an artery flow, the viscosity of blood found to vary with the arterial radius decreasing with it. One may recollect that the diabetic patients are more prone to the various types of cardiovascular diseases. The viscosity of the diabetic patients is higher than that of normal. Therefore the blood viscosity of diabetic patients is lowered by regular dose of aspirin or injecting saline water in order to dilute the blood. Thus it appears that the non-Newtonian behaviour of the blood is helpful in the functioning of diseased arterial circulation.

\section{References}

[1] M. Texon, “A homodynamic concept of atherosclerosis with particular reference to coronary occlusion”, vol. 99, no. 418, (1957).

[2] A. G. May, J. A. Deweese and C. B. Rob, "Hemodynamic effects of arterial stenosis", Surgery, vol. 53, (1963), pp. 513-524.

[3] D. Hershey and S. J. Cho, "Blood flow in ridig tubes: Thickness and slip velocity of plasma film at the wall", J. Appli. Physiolo., vol. 21, no. 27, (1966).

[4] D. F. Young, "Effects of a time-dependent stenosis on flow through a tube”, J. Eng. India. Trans. ASME, vol. 90, (1968), pp. 248-254.

[5] J. H. Forrester and D. F. Young, "Flow through a converging diverging tube and its implications in occlusive vascular disease”, J. Biomech., vol. 3, (1970), pp. 297-316.

[6] C. G. Caro, J. M. Fitz-Gerald and R. C. Schroter, "Atheroma and arterial wall shear observation, Correlation and proposal of a shear dependent mass transfer mechanism for Atherogenesis”, Proc. R. Soc., vol. 177, (1971), pp. 109-159. 
[7] D. L. Fry, "Localizing factor in arteriosclerosis”, In atherosclerosis and coronary heart disease, NewYork: Grune Stratton, vol. 85, (1972).

[8] D. F. Young and F. Y. Tsai, "Flow characteristics in models of arterial stenosis-II, unsteady flow", J. Biomech., vol. 6, (1973), pp. 547-558.

[9] J. S. Lee, "On the coupling and detection of motion between an artery with a localized lesion and its surrounding tissue”, J. Biomech., vol. 7, (1974), pp. 403.

[10] L. K. Richard, D. F. Young and N. R. Chalvin, "Wall vibrations induced by flow through simulated stenosis in models and arteries”, Biomech., vol. 10, no. 431, (1977).

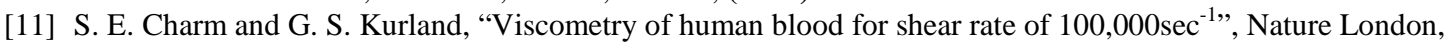
vol. 206, (1965), pp. 617-618.

[12] D. Hershey, R. E. Byrnes, R. L. Deddens and A. M. Roa, "Blood rheology: Temperature dependence of the power law model”, Paper presented at A.I.Ch.E. Boston, (1964).

[13] R. L. Whitmore, "Rheology of the circulation”, Perg NewYork, (1968).

[14] G. R. Cokelet, “The rheology of human blood”, Biomechanics, Ed. By Y. C. Fung et al., 63, Englewood Cliffs: Prentice-Hall, (1972).

[15] M. M. Lih, “Transport Phenomena in Medicine and Biology”, Wiley, New York, (1975).

[16] J. B. Shukla, R. S. Parihar and S. P. Gupta, "Biorheological aspects of blood flow through artery with mild stenosis:Effects of peripheral layer”, Biorhe, vol. 17, (1990), pp. 403-410.

[17] N. Casson, "A flow equation for pigment oil suspensions of the printing ink type", Rheology of disperse systems, Ed. Mill., C.C., London, (1959), pp. 84-102.

[18] M. Reiner and G. W. Scott Baldair, "The flow of the blood through narrow tube", Nature, London, vol. 184, (1959), pp. 354-359.

[19] M. Labarbera, "Principles of design of fluid transport systems in zoology", Science, (1997), pp. 992-1000.

[20] K. Haldar, "Effects of the shape of stenosis on the resistance to blood flow through an artery", Bull, Mathe. Bio., vol. 47, (1985), pp. 545-550.

[21] G. Pontrelli, "Blood flow through an axisymmetric stenosis”, Proc. Inst Mech. Eng, Part H, Eng Med., vol. 215, (2001), pp. 1-10.

[22] P. N. Tandon, P. Nirmala, M. Tewari and U. S. Rana, “Analysis of nutritional transport through a capillary: Normal and stenosed”, Compu. Math. Appli., vol. 22, no. 12, (1991), pp. 3-13.

[23] H. Jung, J. W. Choil and C. G. Park, "Asymmetric flows of non-Newtonian fluids in symmetric stenosis artey”, vol. 16, (2004) June 2, pp. 101-108.

[24] R. N. Pralhad and D. H. Schultz, "Modelling of arterial stenosis and its applications to blood diseases", Math. Biosci., vol. 190, (2004), pp. 203-220.

[25] K. Venkateshwarlu and J. Anand, "Numerical solution of unsteadyblood flow through an indented tube with atherosclerosis”, Indian J.Biochem. Biophys., vol. 41, (2004), pp. 241-245.

[26] D. C. Sanyal, K. Das and S. Debnath, "Effect of magnetic field on pulsatile blood flow through an inclined circular tube with periodic body acceleration”, J. Phys. Sci., vol. 11, (2007), pp. 43-56.

[27] V. P. Rathod and S. Tanveer, "Pulsatile flow of couple stress fluid through a porous medium with periodic body acceleration and magnetic field”, Bull. Malays. Math. Sci. Soc., vol. 32, no. 2, (2009), pp. 245-259.

[28] B. Singh, P. Joshi and B. K. Joshi, "Blood flow through an artery having radially non-symmetric mild stenosis”, Appl. Math. Sci., vol. 4, (2010), pp. 1065-1072.

[29] B. K. Mishra and N. Verma, "Effect of stenosis on non-Newtonian flow of blood in blood vessels", J. Basic Appl. Sci., vol. 4, no. 4, (2010), pp. 588-601.

[30] J. Singh and R. Rathee, "Analytical solution of two-dimensional model of blood flow with variable viscosity through an indented artery”, Int. J. Phys. Sci., vol. 5, no. 12, (2010), pp. 1857-1868. 